\title{
Pensamiento crítico y lectura. Una mirada desde la obra de Guillermo Hoyos-Vásquez*
}
Critical Reading and Thinking. $A$
Look from the Work of Guillermo Hoyos-
Vásquez

\author{
Pensamiento \\ crítico e leitura. \\ Um olhar desde a \\ obra de Guillermo \\ Hoyos-Vásquez
}

Fredy Hernán Prieto Galindo** https://orcid.org/0000-0001-9738-5653

* Una primera versión de este texto se presentó en el Tercer Congreso Latinoamericano de Filosofía de la Educación (2015) en la Ciudad de México y fue publicado en las correspondientes memorias bajo el título Pensamiento Crítico en Latinoamérica: desde el pensamiento de Guillermo Hoyos Vásquez

** Licenciado en Filosofía de la Universidad de San Buenaventura. Actualmente, estudiante de Doctorado en Educación en la Universidad de Alberta (Canadá). Miembro activo Prácticas Filosóficas, grupo de investigación en didáctica de la filosofía de la Universidad Pedagógica Nacional.

Correo electrónico: fhprietog@pedagogica.edu.co

Prieto Galindo, F. (2021). Pensamiento crítico y lectura. Una mirada desde la obra de Guillermo Hoyos-Vásquez. Folios, 53. https://doi.org/10.17227/folios.53-10916
Artículo recibido $05 \cdot 10 \cdot 2019$

Artículo aprobado $08 \cdot 06 \cdot 2020$ 


\title{
Resumen
}

En este artículo de reflexión se propone un modelo filosófico y pedagógico de pensamiento crítico para una escuela impertinente. Para ello nos valemos de la lectura que hizo Guillermo Hoyos-Vásquez de la fenomenología, el idealismo alemán y la teoría crítica frankfurtiana para la situación latinoamericana. En efecto, el pensador colombiano ha propuesto una manera impertinente, crítica y utópica de comprender la filosofía en vistas de la educación escolar y profesional. Estas se han enfocado en satisfacer las demandas del sistema económico-político, han acudido a un concepto cognitivista de pensamiento crítico como una herramienta pertinente para el logro de nuestras utopías sociales y han ignorado el ethos de nuestros estudiantes y su situación existencial.

\author{
Palabras clave \\ impertinencia; pensamiento crítico; utopía; escuela; situación
}

\begin{abstract}
In this reflective article, a philosophical and pedagogical model of critical thinking for an impertinent school is proposed. To do this, we use Guillermo Hoyos-Vásquez's reading of phenomenology, German idealism, and Frankfurt's critical theory for the Latin American situation. Indeed, the Colombian thinker has proposed an impertinent, critical, and utopian way of understanding philosophy in view of school and professional education. These have focused on satisfying the demands of the economic-political system, have resorted to a cognitivist concept of critical thinking as a pertinent tool for the achievement of our social utopias, and have ignored the ethos of our students and their existential situation.

Keywords

impertinence; critical thinking; utopia; school; situation

Neste artigo de reflexão, é proposto um modelo filosófico e pedagógico de pensamento crítico para uma escola impertinente. Para isso, usamos a leitura da fenomenologia, do idealismo alemão e da teoria crítica de Frankfurt para a situação latinoamericana que fez Guillermo Hoyos-Vásquez. Em efeito, o pensador colombiano propõe uma forma impertinente, crítica e utópica de entender a filosofia em vista da educação escolar e profissional. Estes se concentraram em satisfazer as demandas do sistema político-econômico, recorreram a um conceito cognitivista de pensamento crítico como ferramenta relevante para a realização de nossas utopias sociais e ignoraram o ethos de nossos alunos e sua situação existencial.
\end{abstract}

Abstract

\section{Resumo}

\section{Palavras chave}

impertinência; pensamento critico; utopia; escola; situação 


\begin{abstract}
No solo la filosofía, la educación en general
y la universidad especialmente deben ser impertinentes y cuanto más impertinentes tanto más críticas y tanto más abiertas a la utopía.

La teología, la psicología, las ciencias sociales y el derecho han de ser impertinentes,

si quieren ser responsables con una sociedad que espera precisamente de la educación análisis críticos, propuestas de cambio, compromiso con aquello que nos falta en un horizonte de utopía
\end{abstract}

(Hoyos, 2009, p. 427)

Guillermo Hoyos-Vásquez, como nos muestra el exordio, nos invita a re-pensar la educación, el conocimiento y la misma existencia humana. La crítica y la apertura a la utopía constituyen, según el filósofo colombiano, una de las misiones de la formación, del conocimiento y de cada uno de nosotros si queremos lograr una "vida buena". Ante esto, es claro que actualmente uno de los focos de la crítica es la noción de lo pertinente y por eso mismo Hoyos-Vásquez nos sugiere ser impertinentes en lugar de seguir una pertinencia social y educativa que cada vez aumenta las brechas de inequidad, injusticia y malestar: "prefiero ser impertinente de acuerdo con Horkheimer para quien la filosofía cuanto más inútil, tanto más filosofía" (2012a, p. 19). Desde tal perspectiva, la filosofía y educación hoy están llamadas a ser impertinentes, inútiles.

El pensador colombiano critica el "nuevo" uso del adjetivo pertinente cuando se refiere a situaciones en las que parece justificar la injusticia o inequidad. Así, para el gobierno de turno lo pertinente parece ser mantener el statu quo y dejar de lado su responsabilidad con los ciudadanos que se ven atropellados por quienes solo buscan la productividad y funcionabilidad del aparato social para sí mismos. En tal contexto no hay otra salida que ser impertinentes, que denunciar aquello que no va bien en la sociedad, en lugar de ser útiles a un sistema que no nos hace bien a todos.

Se trata de mostrar lo que no pertenece a un Estado saludable y justo. En efecto, lo impertinente es lo que no pertenece de suyo al fenómeno estudiado, no porque este fuera de una supuesta esencia universal o una racionalidad universal, sino porque no contribuye con el compromiso de cambio en la búsqueda de realización de las mejores utopías. Más allá, Hoyos-Vásquez (2009) también piensa, y con más insistencia, en la pertinencia que ha cobijado las orientaciones educativas.

Recientemente, parece que el indicador reina de la responsabilidad social universitaria y en general de la educación es pertinencia. Es el eufemismo para no decir su funcionalidad en otros tiempos para la industria militar y el desarrollo de la productividad, luego para la seguridad nacional. (Hoyos-Vásquez, 2009, p. 427)

Universidades pertinentes, agencias de conocimiento e investigación pertinentes, exámenes estandarizados pertinentes. Todos estos instrumentos ahora parecen querer legitimar un tipo de educación que se reduce al cultivo de un pensamiento instrumental, y unas técnicas y ciencias productivas. Así solo se dejan de lado otros saberes y disciplinas que, además de contribuir, son fundamentales en el espacio educativo de formación donde las nuevas generaciones crecen y son capaces de imaginar otras utopías; con esa orientación pueden comprometerse con el cambio, con una sociedad más justa, más equitativa y saludable para todos.

Hoy en día requerimos ser impertinentes para ser responsables con nosotros mismos y con los otros que están a nuestro lado, con quienes nos sucederán en el futuro. Por supuesto, una institución no puede quedarse bajo el eufemismo de la pertinencia es la universidad, porque ella hace parte del sistema educativo que forma profesionales para la sociedad. Ser pertinente en este contexto sería tanto como ser cómplice del sistema y faltar a su vocación crítica y educativa. Es la impertinencia la que nos llevaría a la responsabilidad con nuestra sociedad, que requiere más y mejores propuestas de cambio. Ahora bien, mientras más impertinentes implica, también, ser más críticos y más abiertos a la utopía, afirma Hoyos en el epígrafe.

Ese es un aspecto que coincide con uno de los objetivos de la escuela contemporánea para formar personas críticas, con la esperanza de lograr una sociedad justa y próspera. Lo cual se logrará en 
la medida en que este tipo de pensamiento pueda contribuir a la democracia, al coadyuvar en la formación de generaciones autónomas y responsables. ${ }^{1} \mathrm{Si}$ bien el pensador colombiano no tematizó explícitamente el pensamiento crítico —como sí es el caso de la Pedagogía Crítica y el Movimiento de Pensamiento Crítico-, se basa en tres filosofías críticas: la fenomenología, el idealismo alemán, y la teoría crítica, de cada una de estas corrientes filosóficas toma elementos que han ayudado a proponer una manera de comprender el pensamiento crítico desde la perspectiva del filósofo colombiano.

¿Cómo entendería Hoyos el concepto de pensamiento crítico en el clima actual de pertinencia? ¿Cuál sería su "propuesta pedagógica" para formar en pensamiento crítico? Tales son las preguntas que orientan este escrito y para responderlas nos orientamos por las principales corrientes filosóficas en las que Hoyos halló un diálogo fructífero y cimentó su pensar filosófico y pedagógico, a saber: la fenomenología, el idealismo alemán y la teoría crítica, convocadas en algunos de sus autores más representativos. De este modo se evidencia, como él mismo afirmó en la introducción a su libro Ensayos para una teoría discursiva de la educación: "es patente el diálogo entre Kant, Husserl y Habermas, autores de los que he aprendido casi todo lo que pienso hoy en filosofía" (Hoyos-Vásquez, 2012a, p. 18).

A partir de tal fundamentación nos arriesgamos a proponer lo que será la tesis de este texto: para Hoyos el pensamiento crítico considera tres dimensiones: por un lado, el pensar, que, en términos kantianos: "va más allá o más acá" del entendimiento y llega hasta la imaginación y el sentimiento moral; por otro lado, con Husserl, es preciso considerar el mundo de la vida, la situación concreta que nos da qué pensar; y, por último, el ejercicio de una comunicación basada en una razonabilidad que acepte e incluso busque argumentos desde otras racionalidades, otras culturas, es decir, que considere al otro

1 Para el caso colombiano, basta mirar la Ley general de Educación en su numeral noveno del apartado Fines de la educación, donde se afirma que el mejoramiento cultural y la calidad de vida del pueblo, el progreso social y económico, entre otras cosas, puede lograrse a través del desarrollo del pensamiento crítico. en su diferencia como un interlocutor válido, ya que "somos diferentes y semejantes en la diferencia" (Hoyos-Vásquez, 2012b, p. 23).

Estas nociones de pensamiento crítico parecen acordes con la concepción que el profesor Hoyos tenía de una filosofía en y para América latina, en la que resalta las situaciones concretas, los males actuales latinoamericanos, que requieren pronta atención:

Pienso que no se puede filosofar en América latina hoy haciendo abstracción de las injusticias y las desigualdades, las exclusiones y discriminaciones, e ignorando las luchas por el reconocimiento, por la emancipación, la inclusión y la democratización de nuestras diferentes formas de vida. (2012b, p. 25)

Es claro que no podemos filosofar ignorando estas situaciones en nuestra tierra, como tampoco podemos entender el ejercicio filosófico solamente como la tematización de un mundo de la vida particular; somos convocados por la reflexión filosófica a ir más allá del mero entendimiento para pensar, imaginar, sentir y comprometernos con la utopía de una sociedad mejor. Se trata de una filosofía que no se funda en la búsqueda metafísica de la esencia o substancia de los fenómenos, sino de una profundización de la vida cotidiana y sus luchas que requieren de pensamiento crítico y acciones concretas.

Para aproximarse a la propuesta del pensador colombiano a continuación se expone: primero, el concepto de pensamiento crítico que podemos inferir desde la reflexión de Guillermo Hoyos Vásquez, a partir de las tres filosofías que nutrieron su pensamiento; segundo, desde la mirada del pensador colombiano revisamos críticamente el ejercicio de la lectura en la escuela y, finalmente, un breve apartado a manera de conclusiones. Sea este texto una invitación para empezar a imaginar y planear estrategias diferentes para aprender a pensar críticamente desde la lectura.

\section{Pensamiento crítico desde Guillermo Hoyos Vásquez}

A partir de las principales tradiciones filosóficas de las que nutrió su pensamiento, Hoyos entendió la filosofía y la educación como un ejercicio que parte 
desde el mundo de la vida y busca pensar desde las utopías de la libertad y la felicidad basado en el diálogo fructífero con quienes piensan diferente (lo que se puede observar en la variedad de filósofos que Hoyos leyó y con quienes dialoga en sus textos). Desde el idealismo alemán hasta la teoría crítica, pasando por la fenomenología, construye un único pensamiento tanto filosófico como pedagógico en el que nos llama a ser impertinentes ante el sistema político-económico de nuestro contexto, displicente con las circunstancias que hacen parte de nuestra identidad latinoamericana, con nuestros logros y nuestros sufrimientos.

Ahora bien, aunque parado sobre hombros de gigantes, el pensador colombiano no plantea una jerarquía entre las filosofías que inspiraron su pensar, así como tampoco propone un procedimiento algorítmico para ser críticos o impertinentes. Al pensar en la filosofía husserliana y la kantiana afirma que:

en términos generales el proyecto fenomenológico de Husserl no supera el proyecto crítico de Kant. En su esquema general esto puede ser cierto, si recordamos que también para Kant un conocimiento trascendental no es tanto un conocimiento directo de objetos, sino un conocimiento de cómo conocemos los objetos. Es decir, la reflexión filosófica no se ubica en el mismo nivel del conocimiento objetivo de las ciencias, sino que de alguna manera pretende explicar y comprender ese tipo de conocimiento de objetos que caracteriza a las ciencias. (HoyosVásquez, 2011, p. 6)

Los dos pensadores alemanes - Kant y Husserlhan criticado el conocimiento, la ciencia de su propio tiempo desde diferentes perspectivas. Kant ha mostrado los límites y alcances de un conocimiento científico válido: el entendimiento y los datos sensibles. Por su parte, Husserl logró ir más allá de Kant al mostrar el fundamento mismo del conocimiento: la subjetividad inmersa en el mundo de la vida. A los dos, el profesor Hoyos-Vásquez (2012b) les critica el hecho de que se quedaran en aquella "ilusión protagónica, vanguardista” de una razón monológica que no logra llegar al reconocimiento del otro. ¿Cómo reconocer al otro, al diferente, si la misma noción de razón como una facultad universal, neutral y objetiva niega la posibilidad de otras racionalidades, otro tipo de razones y maneras de entender-se? Precisamente por esta limitación es que Hoyos aprecia tanto la teoría crítica, en especial el cambio de paradigma de la teoría comunicativa de Habermas. En sus palabras, tal cambio parte "de la filosofía de la conciencia y la reflexión a la 'teoría del actuar comunicacional', es ver si nosotros podemos hacer filosofía y teoría social a partir de los actos de habla, a partir de la comunicación, en lugar de 'a partir de la reflexión"” (Hoyos-Vásquez, 2013, p. 35).

Para Kant y Husserl, se trataba, por tanto, de una filosofía basada en la reflexión, una vuelta de la razón sobre sí misma para encontrarse y creer que ella es la única y fundamento de todo lo humano; ante tal engaño, solo la comunicación con el otro, sin discriminarlo, puede llevar a un pensar abierto y profundo. Entonces, más allá de Husserl y Kant está Habermas y su teoría del actuar comunicacional pero, a su vez, Habermas y Husserl "coinciden en que la reflexión crítica tiene como objetivo afirmar la primacía de la razón práctica con respecto a la razón teórica, en términos de capacidad de responsabilidad (Verantwortungsfälhigkeit) o de interés emancipatorio" (Hoyos-Vásquez, 2011, p. 6).

En efecto, el fin último de la crítica o del pensamiento crítico para el filósofo colombiano no es simplemente develar o denunciar una afirmación o situación contradictoria, falsa o inadecuada, sino modificar o producir ciertas acciones, que para el pensador son primordialmente la realización de la libertad y responsabilidad. Por ello, la reflexión sobre la razón práctica no puede evadirse ni obviarse, sino incluirse como una dimensión necesaria de la(s) filosofía(s) y sistemas educativos para Latinoamérica, para nuestro mundo de la vida. No se trata de un segundo momento de un procedimiento o una parte añadida a la primera dimensión fenomenológica enunciada aquí, sino de la explicitación de un interés que ya se encuentra en la crítica de Husserl: actuar responsablemente ante el mundo de la vida.

Así, ni Kant ni Husserl y mucho menos Habermas están uno por encima del otro; en su lugar, Hoyos rescata los aportes que encuentra en cada uno de ellosy 
los integra en una única "propuesta educativa", como se revelará enseguida. Ahora bien, ¿Cómo ser pensadores críticos desde el pensamiento de Hoyos, para "retornar el pensar a su elemento"? ¿Cuál es el aporte particular que nuestro pensador latinoamericano nos sugiere para pensar críticamente? O, dicho de otra manera, ¿Cuál es la vigencia de la fenomenología, el idealismo alemán y la teoría crítica en relación con la educación del pensamiento crítico y nuestra realidad latinoamericana en general?

\section{Desde la fenomenología}

En honor al lema husserliano, Hoyos propone "volver a las cosas mismas" para hacer filosofía y - podríamos añadir - para hacer pedagogía; se parte de las cosas mismas, es decir, de la experiencia misma que vive la persona en su cotidianidad, para lo cual es preciso dejar de lado la actitud natural. La cosa misma es la realidad ético-política latinoamericana. En última instancia, se trata de tematizar la vida misma en medio de la diversidad social y cultural que se encuentra en la diferencia y su reconocimiento.

La educación debe retornar el pensar a su elemento, el mundo de la vida, la sociedad civil y su eticidad, la dimensión estética, el diálogo y la comunicación, en una palabra la constitución moral de la persona humana, precisamente para que la conciencia moral pueda llevarnos a la idea de libertad y esta a su vez nos abra al sentido de responsabilidad moral. (Hoyos-Vásquez, 2012b, p. 19)

En efecto, para Guillermo Hoyos la educación actual se aleja del pensar o, para decirlo con la metáfora heideggeriana tan querida por el pensador colombiano, "el pensar está en lo seco":

Se juzga al pensar según una medida que le es inadecuada. Este juzgamiento se asemeja al procedimiento que intenta aquilatar la esencia y virtud del pez en vista del tiempo y modo en que es capaz de vivir en lo seco de la tierra. Hace tiempo, hace demasiado tiempo, que el pensar está en lo seco. (Heidegger, 1981, p. 67)

La escuela parece valorar su pertinencia al reducir el pensar a una razón instrumental y por ende es necesario retornarlo a su elemento, el mundo de la vida. Hoyos resignifica este concepto "como ámbito propio de una humanidad no instrumentalizada, es decir, no colonizada por la ciencia y la técnica" (Serna, 2013, p. 22). Solamente al contemplar al ser humano en su situación originaria, a saber, en medio del mundo de la vida que lo constituye, y que él mismo re-configura constantemente, es posible que la educación oriente prudentemente la constitución moral de la persona y, así, su libertad y responsabilidad. En este sentido:

Retornar el pensar a su elemento, en términos de Guillermo Hoyos, implicaría liberarlo de aquella racionalidad que únicamente obedece al mandato de su inercia. (...) Sometido a la inercia del mercado, el pensar no piensa, es decir, no es pensar, sino simple cálculo egoísta. (Serna, 2013, p. 23)

Pensar de nuevo o retornar el pensar a su elemento es dejar aquella actitud que se ha vuelto natural: la del modelo neoliberal que nos lleva solamente a calcular el nivel de ganancia o utilidad que se puede obtener y, por este camino, nos olvidamos del otro y de nosotros mismos y pasamos por encima de ambos. Actualmente, "se sigue insistiendo en la pertinencia, la que garantice sostenibilidad: sostenibilidad del modelo económico que hace crisis" (Hoyos, 2009, p. 428). Dejar este camino, tematizar las cosas mismas, el mundo de la vida, implica abandonar tal actitud natural, en términos husserlianos, hacer epojé. Se trata de enfocar la mirada hacia la situación misma de lo humano, es decir, nuestros problemas latinoamericanos, para admirarnos de ellos, para sentir con el otro que vive y que sufre. Se requiere, entonces, una "nueva actitud" hacia el mundo circundante.

Esta nueva actitud del hombre con respecto a su mundo circundante debe ser motivada por un interés crítico de los intereses inmediatos, porque normalmente el hombre se encuentra en actitud natural, dirigido a su mundo sin prestar atención a éste su estar dirigido a él. (Hoyos-Vásquez, 2012a, p. 143)

Aquí los sentimientos morales tienen un lugar primordial y preponderante: serán los que motiven el cambio de actitud hacia el mundo de la vida y 
encaucen la crítica. El pensamiento crítico comienza allí donde la admiración y el sentimiento moral ante la injusticia y el dolor del otro nos motivan a hacer del mundo de la vida el tema de nuestra re-flexión. $\mathrm{Al}$ hacer énfasis en la dimensión práctico-moral del pensar y del conocimiento, Hoyos se aleja del sentido de pertinencia que llama a concentrarse en la productividad positivista que solo favorece el sistema económico y disminuye la capacidad humana de sentir: de la empatía, la simpatía con el que sufre. "Nuestro interés por destacar en la fenomenología la temática de la cotidianidad, como la desarrolla Husserl, radica en la posibilidad de relacionar desde ella el sentido de la crítica al positivismo científico en la fenomenología" (Hoyos-Vásquez, 2011, p. 6).

Es evidente, pues, que Hoyos percibe el sentido de la crítica de Husserl hacia el positivismo como el olvido del mundo de la vida. La crítica, o mejor, el pensamiento crítico que encarna Husserl lo retoma Hoyos en su propia vida y filosofía al ejercer con vehemencia la crítica a dicha positivización del saber que en el caso colombiano se hace cada más patente. Ejemplo de ello lo encontramos en su reflexión sobre el ethos de la universidad desde un rápido análisis histórico:

En efecto, ni la universidad modernizante que redujo muy afanadamente la modernidad a mera modernización, ni la revolucionaria que en su fundamentalismo no pudo diseñar alternativas políticas de cambio, ni la narcisista que todavía no logra reencontrarse con el país real, ni la neoliberal que sigue buscando un futuro al final de la historia, han podido relacionarse con la sociedad civil, con esa de carne y hueso a la que pertenecemos $y$ a la que de todas formas se debe la universidad del progreso, la del cambio, la de la excelencia y la de la política. (Hoyos-Vásquez, 2003, p. 2)

A juicio de Hoyos, la universidad colombiana en su historia y diferentes "versiones" ha ignorado la realidad del país y han omitido a la persona "de carne y hueso" para privilegiar solamente algunos elementos de la persona como la técnica, la economía, el poder, etc. y abandonar, así, la dimensión moral. Si el pensador colombiano tiene en cuenta a Husserl es por su crítica al olvido del mundo de la vida y por allí comienza él mismo. En este punto, Germán
Vargas Guillén se pregunta qué quedaba para Hoyos de la vasta obra de Husserl, de la fenomenología, a lo que responde:

Queda el título fuerte Mundo de la vida, siempre que este se entienda como horizonte de los horizontes que es vivido desde la perspectividad de las perspectivas. Si se ve así el Mundo de la vida, por igual, se revela como terreno universal de creencia; así, la ciencia es un tipo de doxa que parte de la experiencia de los sujetos en él. De este modo, la condición de dialogicidad implica que el mundo de la vida se nos da subjetiva-relativamente. (Vargas, 2014, p. 14)

En efecto, Husserl nos ha recordado que estamos en el mundo de la vida antes que en cualquier otro mundo (como el mundo académico, el mundo onírico, el mundo de los griegos, etc.). "Es el mundo de la vida histórico, del cual podemos hablar y narrar. Sobre él ejerce el filósofo critica [sic] y busca verdades" (Hoyos-Vásquez, 2012a, p. 34). Es justamente el mundo de la vida el que se da como horizonte fundamental, sine qua non de cualquier perspectiva o posición personal. Entonces, esta no solo es la perspectiva dominante, sino el fundamento mismo de nuestras creencias y del mismo conocimiento científico, pues también la ciencia se funda en una perspectiva ante la imposibilidad de una posición absolutamente neutra. El horizonte de la crítica es el mundo de la vida, diría Hoyos.

Ahora bien, como señala Vargas, tal mundo nos es dado en medio de la dialogicidad propia de nuestra humanidad y su relatividad contextual. Nuestra capacidad de diálogo, de entablar relaciones cercanas con el otro, que piensa y siente diferente, acentúa Hoyos, nos dona el mundo de la vida y nos da la posibilidad de entender lo que sucede en el mundo natural y de pensar otras posibilidades, de imaginar desde la libertad y la responsabilidad que logramos crear. "Lo que se espera es que en la discusión se aprenda a reconocer al otro como diferente y a tener en cuenta sus razones y motivos, de suerte que se llegue a ciertos consensos sobre mínimos y se respeten los disensos" (Hoyos-Vásquez, 2003, p. 11). Esta diferencia entre entender y pensar la resalta desde la filosofía kantiana, como veremos enseguida. 
Atender a las cosas mismas es también reconocer al otro desde los sentimientos morales que experimentamos al ver como lo tratan. Hoyos nos habla de un sentimiento particular: indignación.

La sentimos usted y yo cuando nos damos cuenta de que un tercero injuria a otro como si lo hubiera hecho con usted o conmigo. Lo interesante en este sentimiento es que la ofensa es considerada independientemente de que tuviera que ver con nosotros mismos; en este escenario somos espectadores, pero no de algo objetivo, sino de algo intersubjetivo, y la indignación nos descubre una especie de implícito de solidaridad humana. (Hoyos-Vásquez, 2003, p. 9)

Aquí el mundo de la vida se hace patente cuando sentimos como personal una ofensa hecha a un tercero, cuando alguien es victimizado frente a nosotros. Hacer crítica entonces implica un profundo reconocimiento del otro que sufre, implica reconocer las circunstancias que limitan la posibilidad de realización del otro y de uno mismo. Por supuesto, la crítica nos llevará a la proyección de un mundo mejor desde la utopía, que espontáneamente se eleva ante las circunstancias que han hecho brotar la indignación ante el otro que sufre. Como se ve, en Hoyos el pensamiento crítico no es un ejercicio exclusivo del pensamiento lógico y objetivo que pretende encontrar los elementos constitutivos y las fallas en un texto argumentativo. El pensamiento crítico puede estar enraizado en la situación concreta del mundo de la vida, en nuestras experiencias cotidianas en las que sentimos con el otro. Pensar críticamente también es sentir, no solo razonar.

\section{Desde Kant y el idealismo alemán}

En segunda instancia, la crítica de Hoyos-Vásquez se alimenta de la filosofía kantiana cuya Crítica de la Razón Pura conduce a dos resultados:

un primer resultado negativo, a saber: referir las pretensiones de la razón especulativa a los límites de la experiencia posible, como ámbito del entendimiento para explicar causalmente todos los fenómenos de la naturaleza, sin traspasar de ninguna forma el mundo sensible. Tal restricción legítima despeja, a la vez, como resultado positivo, la posibilidad de un desarrollo de la filosofía práctica en el ámbito de lo inteligible, en el cual las ideas trascendentales -sobre todo la de la libertad como fundamento ontológico de la moralidad-, sin que tengan que referirse a la experiencia, sí pueden llegar a tener sentido para ser racionales. (2011, p. 10)

Así, la crítica kantiana a la razón pura deja claro que el conocimiento científico requiere de las formas a priori de la sensibilidad y del entendimiento que logran procesar los datos de los sentidos para formar los juicios y, por este camino, se llega al conocimiento de la naturaleza. Pero si no hay datos sensibles sobre objetos como el alma humana o la libertad, sería una transgresión del entendimiento formar juicios sobre ellos. Entonces, ante la imposibilidad de conocer científicamente tales objetos "metafísicos", vemos que podemos pensarlos, imaginarlos, crearlos y, de esta manera, a pesar de no provenir de datos sensibles, pueden tener sentido racional y aquí se funda la ética, en una razón que está "más allá o más acá del conocimiento del mundo con base en conceptos del entendimiento" (Hoyos-Vásquez, 2012a, p. 17).

Desde el pensamiento kantiano y, en general de la modernidad, Hoyos valora el uso legítimo de la razón no solo en términos del conocimiento válido de la ciencia, sino también en cuanto a su uso práctico en la cotidianidad donde puede ayudar a proponer horizontes que doten de significado la acción de la persona. En tal sentido:

la crítica no solo tiene el valor negativo de ayudar a establecer sus [de la ciencia] condiciones de posibilidad, sus límites y su sentido de validez; también tiene el sentido positivo de abrir el horizonte significativo para un uso práctico de la razón. (Hoyos-Vásquez, 2012a, p. 149)

Para Hoyos lo que se vive en la actualidad es una reducción o al menos un énfasis en la manera como se valora el uso teórico de la razón (positivismo) frente al uso práctico (moral), al punto de ignorar la segunda. Tal desequilibrio ha desembocado en la llamada "crisis de la modernidad" en la que se ha 
confundido modernidad con modernización, reduciendo la primera a la racionalidad instrumental y funcional. Como consecuencias de tal confusión,

las promesas de libertad, igualdad y solidaridad de la ilustración no se han cumplido. Todo lo contrario: los holocaustos, la pobreza absoluta, las discriminaciones de toda índole, han sido el resultado de utopías emancipatorias de una razón ilustrada y de un progreso pretendidamente humano. (Hoyos-Vásquez, 1998, p. 77)

Tales resultados llevan a buscar alternativas de solución que evidentemente no pueden ser el abandono del cultivo de la razón teórica o de la ciencia. El cambio que se necesita es buscar la realización del ideal de la modernidad — que también es tolerancia y democracia - como crítica, pues lo que ha hecho falta precisamente es la crítica, pero no la crítica desde posiciones conservadoras que pretenden regresar a los valores de antaño y desechar todo lo ganado. Más bien, escuchar las críticas de quienes desde la posmodernidad han señalado los límites de la razón despótica.

Lo único posible es la crítica, la cual, al preguntar por la 'verdad' de la metafísica, reconoce su significado para el hombre: lo que él no puede conocer, sí puede pensarlo con relación al sentido de la vida y de su actuar en el mundo. (Hoyos-Vásquez, 1998, p. 85)

En efecto, Kant lo dejó claro, solo podemos conocer lo que afecta nuestros sentidos, pero esta limitación abre otras posibilidades en cuanto al pensamiento (no en cuanto conocimiento), pues este no se limita por la información que llega a los sentidos. El pensamiento se nutre de otro tipo de información o de contenidos, como los sentimientos, la imaginación, el deseo. Entonces, para Hoyos, en filosofía y en educación, se trata es de pensar, no solo de conocer; "pensarlo [a la persona] como libre, capaz por tanto de asumir su responsabilidad moral de dar razones y motivos para su acción" (HoyosVásquez, 1998, p. 86). En efecto, al encontrar los límites del conocimiento en el entendimiento, Kant nos ha mostrado el horizonte del pensar desde la ética, entre otros.
En su ética, Kant propone el imperativo categórico, una ley de la razón para actuar en libertad de acuerdo con la ley moral, que solicita tener al otro siempre como un fin y nunca como un medio. Se trata por tanto de no instrumentalizar a la otra persona con el fin de cumplir fines subjetivos, sino de tener presente al otro como fin mismo de las acciones individuales, es decir, buscar siempre los beneficios de mis acciones para el otro, en lugar de ser el perjudicado. Como dice el mismo Hoyos:

volver a la crítica de la razón pura de Kant, para quien más allá o más acá del conocimiento, [...] tiene sentido para el hombre PENSAR: pensar la libertad, el mundo como totalidad, la identidad y la responsabilidad personal, el sumo bien como lo incondicionado de lo condicionado, ámbito de la religión y de utopías sociales y libertarias. (citado por Ruiz y Quintero, 2012, p. 11)

He aquí el papel del pensar: orientar hacia la utopía. 'Profesor. ¿Pero usted todavía cree en utopías?’. Bueno. Creo en utopías en cuanto confío que la acción humana puede ser transformadora" (Hoyos-Vásquez, 2013, p. 40). Pensar críticamente no es solo ejercitar algunas habilidades cognitivas, y determinar el conocimiento válido, sino pensar la utopía, orientar la vida personal y social desde la misma imaginación que puede crear nuevas formas de vivir. Tal pensar orienta la vida desde la esperanza que cree posible la realización de utopías y por ello se las piensa y sirven como orientación de la crítica y de la impertinencia ante el statu quo. Evidentemente, la epojé husserliana no basta para lograr una orientación prudente de la constitución moral de la persona, pues no existe un único ideal de vida buena o felicidad, y por ello mismo un pensamiento instrumental no alcanza a orientar prudentemente hacia el logro de tal fin.

Ahora bien, la ética kantiana por sí sola parece no cumplir con las demandas de un mundo diverso y pluricultural que reclama la comprensión y el diálogo entre diferentes razones y racionalidades. Ciertamente, la filosofía kantiana se cimienta en una concepción monológica de la razón, es decir, un concepto de razón que afirma la universalidad, objetividad y neutralidad de esta. Hijo de su tiempo, 
Kant está convencido que la razón es igual en todos los seres humanos y, por ende, en su universalidad se halla la clave del comportamiento moral y del conocimiento de la naturaleza para todos los seres racionales. Pero esta razón ha caído en descrédito y hemos descubierto que tal racionalidad moderna, producto de la ilustración, no es universal, ni objetiva, ni necesaria: es "un metarrelato más" (HoyosVásquez, 2012b, p. 212).

Aunque Hoyos presenta tal crítica, cree que el imperativo kantiano puede servir de orientación general del comportamiento, como el principio de la no-instrumentalización del otro. Dicho principio vale para cualquier escenario, pero en relación con el ámbito educativo, motivo de la presente reflexión, Hoyos presta atención al opúsculo kantiano titulado Pedagogía, especialmente en lo que concierne a la Educación Práctica o moral, "aquella mediante la cual el hombre debe ser formado para poder vivir, como un ser que obra libremente" (Kant, 2003, p. 45). Allí, el filósofo de Könisberg propone tres dimensiones de la educación en los que hallamos tres espacios o momentos propios del pensamiento crítico.

Esta educación se compone: a) de la formación escolástico-mecánica, que se refiere a la habilidad, entonces es didáctica (instructor) ${ }^{2}$; b) de la formación pragmática, que se refiere a la prudencia (ayo); c) de la formación moral, que se refiere a la moralidad. (Kant, 2003, p. 45)

Ahora bien, estas tres dimensiones de la educación práctica, actualizadas por Guillermo HoyosVásquez se pueden entender así:

Podríamos decir que el fin y la meta de toda educación para la libertad se identifica con el ideal de la ilustración: educar para la mayoría de edad (Mündigkeit). Y esto significa educar desde el punto de vista técnico, pragmático y moral:

2 Es claro que para la época de Kant el concepto de didáctica era mucho más limitado que lo que representa para la pedagogía contemporánea. Para Kant este concepto se limita al conocimiento y labor del instructor, es decir a la enseñanza, excluyendo totalmente la dimensión del aprendizaje y sus procesos conexos, que en la actualidad constituyen el lugar central de la didáctica y pedagogía. Así, al reducir la didáctica a la técnica de enseñanza, muchos licenciados y profesores en la actualidad coinciden con Kant y su comprensión de una didáctica del siglo xvill. desarrollo de habilidades y destrezas para un uso acertado del entendimiento con respecto a la ciencia y la técnica, desarrollo por tanto de la razón instrumental; pero al mismo tiempo desarrollo de todo aquello que conduce a una organización correcta de las instituciones desde el punto de vida de la política y la ética; y finalmente desarrollo de la personalidad, de la identidad personal en la capacidad de realizarse como hombre libre, al reconocerse como ser social. (2009, p. 35)

Por tanto, heredero de los ideales de la Ilustración, nuestro pensador colombiano se aferra al ideal de una educación para la libertad y, de la mano del pensamiento pedagógico de Kant, considera irreemplazable una formación en las habilidades necesarias para las ciencias, al menos las que se trabajan en la escuela. Aquí encontramos, en primer lugar, la razón instrumental que, bajo el modelo del pensamiento crítico, podría constituirse en el desarrollo de ciertas habilidades cognitivas para lograr comprender y producir argumentos y poder criticarlos.

En segundo lugar, tal educación para la libertad requiere de una acertada organización institucional tanto en lo político como en lo ético, que en la escuela puede verse en las instituciones democráticas y participativas en las diversas formas de la vida estudiantil (como la elección de los representantes ante diversas instancias de gobierno escolar, así como la veeduría que pueden ejercer los estudiantes sobre la labor de sus líderes electos, e incluso la denuncia de formas de violencia dentro de la escuela). Desde luego, esta labor política se puede ejercer desde una formación para la ética personal, basada en principios éticos claros, reflexivos y flexibles según la situación y, en ese sentido, apoyados en la virtud de la prudencia.

Finalmente, como tercer rasgo de la propuesta kantiana leída bajo los lentes del pensador colombiano, se halla el desarrollo de la personalidad, de la identidad personal, que puede nutrirse en la escuela desde el espacio que se brinde al estudiante para conocerse y reconocerse en su propia historia, una historia que puede leer cual texto desde las acciones realizadas (Ricoeur, 2010) y que es latente en medio de un corpus social que lo ha constituido y lo sigue constituyendo cada vez. 
Así, desde la riqueza de la filosofía kantiana, Hoyos ha tomado el momento ético como el elemento necesario para complementar el énfasis al conocimiento en favor de la producción. Desde la ética pensamos en el otro para reconocerlo e incluirlo en nuestras consideraciones personales al momento de tomar decisiones; evitamos instrumentalizarlo, pasar por encima de él. Desde una perspectiva más pedagógica, Hoyos se vale del opúsculo kantiano que propone ciertos derroteros para la escuela y la formación de la persona. Aquí nuevamente se trata de evitar el reduccionismo y exclusión que implica el positivismo con su énfasis en el producto del entendimiento y que menosprecia el pensar la libertad, el bien y la felicidad; ahora, estas reflexiones se siguen enmarcando en la persona y su fuero interno. En realidad, aún no hemos avanzado en una verdadera inclusión del otro, tanto de la otra persona en su individualidad como en la posibilidad del Otro como una cultura diferente. Ante esta falencia Hoyos acude a la teoría de la comunicación de la escuela de Frankfurt.

\section{Desde la teoría crítica}

Finalmente, desde la tradición socio-crítica de la escuela de Frankfurt, la crítica para nuestro pensador colombiano implicaba como eje fundamental el ámbito de la comunicación y el entendimiento intercultural, que supera una razón instrumental y se desplaza hacia una razón comunicativa en medio del intercambio de razones con el otro, que siempre puede ser un interlocutor válido. En efecto, "La utilidad de la filosofía en la tradición de la escuela de Frankfurt es la crítica, la misma que motiva a Heidegger a reconducir el PENSAR a su elemento, para nosotros las cosas mismas" (Hoyos, citado por Ruiz y Quintero, 2012, p. 11).

Esto es, llevar el pensar de vuelta al mundo de la vida en lugar de mantenerlo en la inercia del planteamiento neoliberal que exalta la individualidad por encima de la comunidad, el interés y gozo particular a expensas de las consecuencias para el otro.

Tal principio ha llevado a perder la sensibilidad por la situación del otro, el sentir de indignación al ver el sufrimiento del otro. Pero si volvemos al mundo de la vida y reconocemos al otro que habita con nosotros, podemos llegar al diálogo con el otro y reconocer en él y su diferencia la perspectiva que amplía el horizonte personal de comprensión de aquello que se esté examinando. Se trata, entonces, de abandonar una racionalidad que consume la esencia misma de la vida humana y la sustituye por simulacros de felicidad basados en la instrumentalización que reduce el otro a un objeto de dominio y manipulación.

La teoría del actuar comunicacional está de acuerdo con la crítica de los postmodernos a la modernidad. Se reconocen sus reparos a una razón monológica, protagónica, auto reflexiva, pero se considera como solución no un aberrar de la razón, sino dialogizarla, de suerte que en su triple actividad, como comprensión, como argumentación y como aplicación se desarrolle comunicativa, discursiva y pragmáticamente. (Hoyos-Vásquez, 2012b, p. 200)

Así, a pesar de seguir la crítica acérrima a una razón universal que creyó ser el fundamento mismo de un futuro hacia lo mejor, con los tristes resultados atestiguados tempranamente en el siglo XIX, no se trata de dejar la razón, entre otras cosas porque somos seres racionales. Ahora se trata de ampliarla desde el otro, el prójimo, por medio del diálogo en el que las razones no tengan un único modelo de validez, una única perspectiva omnicomprensiva, sino la pluralidad propia del mismo fenómeno humano que se haya materializado en la diversidad de culturas, lenguas, tradiciones. En palabras de Hoyos,

es necesario, por tanto, retornar la educación a su elemento, así parezca irracionalismo apreciarla a partir de la intersubjetividad de la comprensión, de su apertura a las diversas culturas, opiniones, puntos de vista y perspectivas, en una palabra a la dimensión humanista en la que sea posible reconocer al otro en su diferencia como diferente y por tanto como interlocutor válido. Sólo entonces tiene sentido hablar sobre objetividad a partir del diálogo, la argumentación y el discurso intercultural. (2012b, p. 100) 
Entonces, se trata de reconocer al otro que lucha por ser reconocido como diferente, pero no por ello menos valioso en su opinión y perspectiva, sino precisamente tal diferencia asienta la validez de su participación en un diálogo en el que se procura ampliar y profundizar la comprensión del fenómeno o situación humana. Educar, por ende, conlleva la necesidad de poder guiar a los estudiantes por los senderos de la diversidad en los que las razones y opiniones reflejan la pluralidad misma de las culturas humanas y sus comprensiones sobre la vida. "Habermas nos va a mostrar que conversando, comunicando, dialogando yo puedo acceder a «lo racional» y «lo razonable». Habermas dice: «¿eso cómo se logra?» Comunicando" (Hoyos-Vásquez, 2013, p. 37). Pero, ¿qué es comunicar? Y antes de eso, ¿cuál es la diferencia entre lo racional y lo razonable? Aunque Hoyos reconoce que la diferencia de estos conceptos no estaba explicita en Habermas, sino que la halló en escritos posteriores de liberalismo político de Rawls, afirma que se hallaban in nuce en el pensamiento habermasiano y así los diferencia:

[...] racional sigue siendo mi racionalidad medios-fines. Para obtener mis fines yo soy racional, yo utilizo los mejores medios, los más eficaces, los más eficientes (...) pero resulta que el otro hace otra cosa que lo justifica racionalmente desde su plan de vida. Entonces yo, en la acción social y política, tengo que tener en cuenta el punto de vista del otro, la racionalidad del otro (...) lo razonable es que desde mi racionalidad yo tenga en cuenta la racionalidad del otro, y de la otra. (Hoyos-Vásquez, 2013, p. 39)

Lo racional, indicaba Hoyos, es una función de la razón, en la que se basa la ciencia y por la que llega a conocimientos válidos. Pero somos más que conocimiento. Hay más funciones de la razón: podemos pensar, dialogar, comunicar. En efecto, comunicar no es simplemente proferir proposiciones declarativas, es decir, dar información unidireccionalmente. "La comunicación es invitar desde mi perspectiva a que otros den sus puntos de vista" (Hoyos-Vásquez, 2013, p. 46). Podemos dar razones para justificar nuestras decisiones o preferencias. Y al dar y escuchar razones, al escuchar a la otra persona y captar su perspectiva, podemos ser razonables y podemos llegar a comprenderla, aunque no estemos de acuerdo con ella. Desde la perspectiva del pensador colombiano, nutrido por el pensar de Habermas, “'lo razonable’ es más importante que 'lo racional' (...) la cultura es más importante que la argumentación (...) las ideas son más importantes que la investigación (...) la libertad es más importante que la causalidad" (Hoyos-Vásquez, 2013, p. 41).

En lo razonable el disenso no resulta inapropiado, ni una barrera a derribar, sino el punto de partida para buscar puntos comunes de diálogo y comprensión en la diferencia. Al lograr aceptar el disenso, la diferencia, logramos aceptar que la riqueza de lo humano está precisamente en tal diferencia y que, al buscar únicamente consenso, probablemente buscamos solamente un reflejo de nosotros mismos en el otro, es decir, eliminar al otro. Como afirma Hoyos: "solo a partir de la comprensión mutua entre diversos puntos de vista, perspectivas y culturas es posible hablar de un pluralismo razonable que permita llegar a acuerdos políticos con base en la deliberación y participación de todos los afectados" (Hoyos-Vásquez, 2012b, p. 113).

Así, la crítica del pensamiento se desenvuelve desde la negación misma de una única racionalidad universal, que lleva al reconocimiento de la diversidad de racionalidades y perspectivas y su valor intrínseco. En consecuencia, una educación hacia el pensamiento crítico se esfuerza por presentar y valorar diferentes posturas desde cada una de ellas sin tratar de reducirlas a una sola ni a un conjunto de perspectivas válidas. ¿Quién tendría la perspectiva divina que medie y defina cuáles son válidas y cuáles no?

Concluimos esta sección con las palabras de Julián Serna a propósito de la relación de Hoyos con la teoría habermasiana:

el profesor Hoyos apuesta por la razón dialógica, la misma que actualiza sus potencialidades como racionalidad comunicativa. Es cuando se desvirtúa la razón en singular, cuando no hay razón sino razones, en contraposición con el 
modelo de racionalidad monológica. De allí la pertinencia de la teoría de la acción comunicativa formulada por Habermas, la cual reconoce a los participantes en la conversación como interlocutores válidos, en la medida en que exponen racionalmente sus pretensiones, $\mathrm{y}$ abre la posibilidad del consenso a pesar y a partir del disenso. (Serna, 2013, p. 22)

Así, desde la teoría kantiana y habermasiana, Hoyos lo que hace es recuperar el uso de la razón más allá del ejercicio epistemológico de la producción del conocimiento válido en la ciencia y la tecnología. Antes que razón monológica, antes que lógica, es más importante la razón que nos lleva a pensar y a encontrar lo razonable en medio de las diferencias personales y culturales. Se trata por tanto de encontrar el espacio para la comunicación en el que todos puedan participar y sean escuchados y sus aportes valorados y pensados, tomados en cuenta para imaginar otras posibilidades de convivencia en medio de la diferencia, sin suprimirla en una supuesta perspectiva universal.

El término "razonable", tradicionalmente es un término aristotélico, basado en la prudencia, y no todo «lo racional» es lo más sensato. Lo sensato es tener en cuenta las diversas racionalidades, diversas lógicas, diversos puntos de vista; eso es lo más razonable. (Hoyos-Vásquez, 2013, pp. 39-40)

En última instancia, el ejercicio del pensamiento crítico en Guillermo Hoyos no es un desenvolvimiento meramente cognitivo de las facultades de la razón. Reside en su raíz un ejercicio ético, de consideración de la vida humana, de la persona como mucho más que una razón que conoce. La persona, el otro y la otra que piensa, imagina, siente que puede transformarse y transformar su entorno. Y en ese pensar lo que se busca es ser razonable con, desde y para el otro. Bien podríamos decir con Hoyos que mientras más apertura halla al diálogo entre varias perspectivas, tanta más crítica y tanta más prudencia. La riqueza del pensamiento crítico no se haya en lo racional de sus fundamentos, sino en la amplitud de apertura para tener en cuenta la diferencia de la otra persona.

\section{La escuela colombiana}

Ahora, en esta sección del documento abordamos el tema de la lectura de textos escritos en la escuela. La educación en la escuela sigue siendo predominantemente texto-céntrica y en ello la filosofía es tanto elogiada como censurada, aunque también se ha nutrido del texto escrito en sus diversos géneros, a pesar de reducirse hoy al artículo científico (Prada, Acevedo y Prieto, 2019). Aprendemos filosofía leyendo y nos evalúan leyendo y escribiendo. Incluso el Ministerio de Educación Nacional ha avalado la Prueba Saber 11 que se concentra en evaluar el pensamiento crítico desde la lectura crítica. Pero ¿cómo está concebido este ejercicio de lectura crítica? ¿Cómo leemos en la escuela? ¿Cómo hacemos filosofía, pedagogía y crítica en la escuela desde los textos escritos allí leídos? ¿Qué creemos que es pertinente enseñar y cómo es pertinente enseñarlo?

Aplicaremos aquí la noción que acabamos de ver de pensamiento crítico desde el pensamiento de Guillermo Hoyos Vásquez; lo pertinente hoy para algunos maestros y pedagogos es confiar en el ideal de una razón ilustrada, especialmente en su dimensión teórica, epistemológica. Se tiende a ignorar las otras funciones de la razón, se ignora la razón práctica, la moral. Además, ante el avance de la psicología cognitiva, e influenciados por ella, perseguimos el desarrollo de las habilidades del pensamiento para lograr formar jóvenes críticos; entonces, solemos quedarnos, o al menos hacer mayor énfasis, en el desarrollo de habilidades del pensamiento (identificar, analizar, sintetizar, argumentar, etc.), pues autoengañados ${ }^{3}$ creemos que al poseer las capacidades o habilidades del pensamiento bien desarrolladas solo bastará que el estudiante las aplique para identificar el bien.

Bajo estas premisas y orientados con ejercicios adecuados, ciertamente los estudiantes desarrollan habilidades como la memoria, la argumentación, la proposición, la interpretación, etc.; pero, ¿cómo ha contribuido la escuela a esta situación? Es decir, ¿qué actividades o métodos pertinentes hemos desarrollado para formar así las mentes de nuestros

3 Para ver la relación entre autoengaño y pensamiento crítico ver El pensamiento crítico y el autoconocimiento (Prieto, 2018). 
estudiantes? Solamente se señalará lo que parece ser la manera más pertinente de orientar en la actualidad el crecimiento de la autonomía y el sentido crítico en los estudiantes: el ejercicio de lectura sobre textos muertos y no sobre los textos vivos de nuestra realidad.

En efecto, parece que los estudiantes han logrado revelar la estructura de un texto cualquiera: identifican su tesis, argumentos y derivadas; valoran la coherencia entre tales elementos, y entre estos con la vida misma. Sin embargo, no piensan, no van más allá del mero ejercicio del entendimiento, y así, no imaginan la utopía como tampoco llegan hasta el compromiso. No sienten con el otro, no hay empatía ni simpatía, sino más bien antipatía hacia el otro, pues no son capaces de imaginar que pueden estar en su lugar. Entonces, se quedan en la razón teórica, en lo que hoy llamamos la mera cognición y no llegan a una razón práctica que podría llevarlos a la autonomía y responsabilidad para con su propia sociedad. Veamos esta situación desde el ejercicio escolar de la lectura.

\section{Textos vivos en la escuela}

Lo pertinente en la escuela es la lectura micro y macroestructural sobre textos muertos y no sobre textos vivos. Pero ¿qué es un texto muerto, y qué un texto vivo? Probablemente pensamos que la vida de un texto se encuentra en su motivación para mover el pensamiento: en su capacidad de generar polémica, de ir en contra de lo establecido o, al menos, en su capacidad de ponernos a pensar. Ciertamente aquí hay vida. Pero tal vida o vivencia de un texto, de su lectura se deja de lado cuando lo embalsamamos en medio de análisis micro y macroestructurales. Dividimos el texto en sus elementos constitutivos: tesis-argumentos-derivadas; inicio-nudo-desenlace; protagonista, antagonista, tiempo, espacio, recursos literarios; etc. Entonces, leemos textos muertos, embalsamados en su estructura interna.

Le pedimos al estudiante que relacione explícitamente los contenidos del texto con la realidad nacional, con lo que ve en los comportamientos de otros. Después de cierta práctica, por supuesto los estudiantes aprenden a desarrollar tales análisis y relaciones explícitas, pero su vida sigue igual. De manera que el texto, así como su análisis objetivo y pertinente, no ha hecho mella en ellos, ha quedado tan muerto como resultado de la disección realizada en el análisis estructural. En medio de tales ejercicios, el pensamiento siempre se queda en planos metafísicos academicistas que mueven el entendimiento por un momento, pero no mueven la voluntad ni la sensibilidad. En medio del análisis estructural del texto, las relaciones con la vida personal se convirtieron en un apéndice teórico del texto leído, por ende, un elemento más del texto sobre el cual se da cuenta en el examen, esa es su utilidad. Lo pertinente al leer parece ser aniquilar el texto buscando la anhelada e imposible tarea de la objetividad, neutralidad e imparcialidad.

Por supuesto, no se trata de eliminar el análisis micro y macroestructural, pues ciertamente ayuda a los estudiantes a reconocer ciertos elementos del texto y les permite realizar lecturas más profundas, al tiempo que desarrolla sus habilidades cognitivas. Pero empezar por allí, enfatizar tal procedimiento, parece simplemente embalsamar, disecar y fragmentar el contenido; esto es, aniquilar la posibilidad del disfrute estético y emotivo del mismo. Es posible que sea más llamativo para el estudiante que se le pregunte por lo que sintió o imaginó, por su vivencia, su experiencia de lectura; participar de la lectura del texto, de las impresiones que dejó en el estudiante puede llevar a otros, a los compañeros de clase a encontrar situaciones semejantes de su cotidianidad; tal vez injusticias o, por el contrario, alegrías y motivos de transformación. Es aquí donde los textos se vuelven textos vivos.

Un texto es o se hace vivo cuando hace parte de nuestra manera de sentir y vivir el mundo, cuando ya no nos sentimos igual después de comprenderlo, sobre todo, cuando ha dejado de ser mera información y empieza a transformarse en sentimientos y decisiones concretas ante el propio existir, sobre todo en la acción de la crítica a sí mismo. No se trata, por supuesto, de encontrar verdades absolutas y actuar en su defensa y difusión o imposición. Hacer vivo un texto es llevarlo a la vida vivida. Con el ánimo de parafrasear a Paul Ricoeur (2003), un texto vive 
cuando yo con-figuro y re-figuro mi existencia a la luz del mundo del texto que se proyecta ante nosotros y el mundo que nosotros podemos proyectar o recrear en su lectura. Si se quiere, se trata de configurar la propia filosofía de vida a partir de los textos que leemos en la escuela. Pero en la escuela lo pertinente es desarrollar las habilidades del pensamiento, sin importar en qué ámbitos u objetos se han de ejercitar.

En esto, Hoyos sí sabía cómo llevar la teoría al estudiante. Como ávido lector de las noticias y sucesos político-sociales, académicos y a veces "triviales", este pensador siempre nutría sus lecciones de filosofía con los hechos relevantes y no relevantes del momento. Sus textos en clase no se limitaban a las fuentes pertinentes para aprender lógica, o teoría crítica o fenomenología, sino que acudía a los textos del contexto colombiano, a las luchas cotidianas del ciudadano de a pie. Ejemplo paradigmático de ello se ha publicado póstumamente bajo el título de Filosofía de la Educación. Apuntes de su último seminario de doctorado (2013), donde algunos de sus estudiantes nos dejan conocer lo que Hoyos les compartió en aquel seminario: no solo su perspectiva de la ética comunicativa, sino su propio método de enseñar o mostrar la cercanía entre teoría y práctica, entre ciencia y vida. Allí nos habla del paro indefinido, de la protesta estudiantil, de la guerrilla y sus ideales, de la democracia, etc. Germán Vargas Guillén lo explica así:

metodológicamente, la obra de Hoyos -sobre todo en lo que cuenta como parte de su filosofía de la educación, sus escritos sobre ética y sobre política- está salpicada de noticias, de observaciones de la vida cotidiana, sobre las valoraciones de las actuaciones de los personajes de la vida pública de los colombianos, latinoamericanos y de ciudadanos de diversos estados, de los ciudadanos del mundo. (2014, p. 14)

Vemos cómo Hoyos no se quedaba simplemente en mencionar lo que escuchaba en las noticias o leía en periódicos, sino que mostraba sus sentimientos, su indignación y sensibilidad ante lo que consideraba injusto o inadecuado, que criticaba y denunciaba sin ambages; además, proponía los ideales o utopías que consideraba podrían reemplazar la situación que comentaba. Así, en su lectura de la teoría comunicativa de Habermas no se limitaba a encontrar los elementos estructurales del texto y hallar relaciones lógicas con la realidad social, sino que sentía profundamente lo que pasaba en el país y el mundo, y lo llevaba a clase con los textos de las situaciones sociales que resultaban impertinentes en una escuela que trata de ser objetiva y neutral, una escuela que le teme a pensar diferente desde el ideal utópico que la imaginación puede proyectar.

El ejercicio de la lectura no se queda en la mera interpretación del texto, en adivinar lo que supuestamente el autor del texto nos quiso decir; ciertamente se trata de oponerse al ejercicio de la lectura que pone el acento en la interpretación y por ende rechazamos, como diría Estanislao Zuleta (2005): "toda concepción naturalista e instrumentalista de la lectura: recibir, consumir, adquirir" (p. 78). O sea, absorber información sin lograr relacionarla con la propia vida es una lectura con la que solo se busca saber cosas, pero no aspira pensar los problemas que aquejan nuestra existencia personal y social para imaginar diferentes posibilidades utópicas que nos lleven por otros caminos.

Un ejercicio valioso de lectura requiere "un lector que no sea solamente cuidadoso, 'rumiante', capaz de interpretar, sino también capaz de permitir que el texto lo afecte en su ser mismo, le hable de aquello que pugna por hacerse reconocer aun a riesgo de transformarlo" (Zuleta, 2005, p. 82). Esta posibilidad de que el texto nos afecte e incluso nos transforme es el punto inicial de un pensar impertinente, de una lectura crítica que vaya más allá de las estructuras del entendimiento y llegue hasta los horizontes de las ideas utópicas de libertad y felicidad ante las situaciones de injusticia social que vivimos cada día.

El peligro de una lectura que se queda en la interpretación y análisis estructural de un texto es promover el statu quo, mantener la situación personal y social tal como ella se ha desarrollado en oposición a la realización de la libertad de los individuos y a la posibilidad de conocerse a sí mismos y edificar su propia identidad desde lo que ellos mismos desean ser y no desde lo que el sistema impone. Así: 
toda lectura 'objetiva,' 'neutral' o inocente es en realidad una interpretación, que conlleva de por sí una dislocación de las relaciones internas de un texto, resultado de la traducción del significado de sus términos a la interpretación previa de una ideología dominante. (Zuleta, 2005, p. 80)

Pero hay otros textos vivos: los de nuestro presente, que suelen quedarse fuera del aula y de la discusión con nuestros estudiantes. ${ }^{4}$ Los textos que narran las injusticias y problemas de nuestros compatriotas; lo que escuchamos o vemos en la calle, en los noticieros, en el periódico y nos conmueve, nos altera, nos indigna, parece quedar por fuera del currículo, porque parece no tener relación con la historia de la colonia, el aparato digestivo, o las mónadas de Leibniz y - paradójica e incomprensiblemente- con los cursos de política, ética y competencias ciudadanas.

En nuestro afán por cumplir con un conjunto de temáticas preestablecidas, los estándares del Ministerio de Educación Nacional, por ser objetivos y enseñar lo que se ha calificado como pertinente, los profesores dejamos de lado los textos vivos de nuestra realidad latinoamericana. Tal vez bajo la excusa de la objetividad o bajo el temor de no caer en adoctrinamientos ideológicos de la creencia de turno. Tal vez queremos ser neutrales, imparciales, objetivos (como si pudiésemos despojarnos de nuestra subjetividad cuando entramos a un salón de clase), pero en realidad con tal actitud solo dejamos abierto el espacio de lo público para que quienes no buscan la imparcialidad y la objetividad hagan lo que desean en pro de sus intereses particulares. En efecto, al declararnos imparciales o neutrales y omitir en nuestras clases los textos de nuestras realidades no solo colaboramos deliberadamente con su desconocimiento y omisión, sino que dejamos sin

4 Después de haber sido aceptado para publicación este texto, me encontré con una investigación realizada en un colegio colombiano sobre la formación del pensamiento crítico con lo que aquí he llamado textos vivos. Esta investigación ofrece elementos interesantes para repensar la formación del pensamiento crítico desde otro tipo de textos en las clases de humanidades. Ver: Lara, J. y Rodríguez, E. (2016). Fomento del desarrollo del pensamiento crítico en estudiantes de grado décimo desde situaciones cotidianas en la asignatura de Filosofía. Revista Educación y Humanismo, 18(31), 343-357. http://dx.doi.org/10.17081/eduhum.18.31.1383 oposición a quienes sin vacilar propagan discursos manipuladores e ideológicos sobre tal realidad. Entonces, nos hacemos cómplices de ellos. Ante este panorama solo cabe una pregunta: ¿cómo lograr la formación de personas críticas y abiertas a la utopía si nos negamos y les negamos la posibilidad de ser impertinentes?

Ante una escuela que parece ignorar la pluralidad cultural y racional en la que vivimos, como si en verdad existiese una razón universal, como si de verdad fuésemos iguales, Hoyos propone el diálogo de la argumentación razonable. Deja de lado la razón monológica, leer críticamente podría ser el ejercicio de imaginar e investigar cómo pensarían otras personas, otras culturas sobre el asunto del texto, sobre el mundo que proyecta. El propósito aquí es esforzarse por comprender la posición del otro, aquel que no comparte nuestra razón, nuestra cultura. Aquí, invitar a un indígena o un afrodescendiente y entender su opinión y visión del mundo es enriquecedor. Se trata de pensar diferente, desde la diferencia del otro y no desde mi única posición, como si todo el mundo tuviese que acomodarse a mí, pero yo no acomodarme al otro. Para ello, tal vez resulte interesante y motivante para los estudiantes comparar textos con los de otras culturas y encontrar las razones, creencias, sentimientos que les impulsan a hacer lo que hacen, vivir como viven. O sea, tratar de comprenderlos, aunque no estemos de acuerdo con ellos (HoyosVásquez, 2013). ¿Cómo valorar la diferencia del otro y tomarla como válida si no la comprendo, si me quedo con los estereotipos culturales y los clichés que reducen la diferencia al absurdo y la mofa?

Tal vez estos ejercicios tampoco sean pertinentes, porque la Prueba Saber no los mide. Pero, como afirma el pensador colombiano, precisamente por impertinentes es que tienen valor y al estar presentes en el currículo lograrían una educación más abierta y plural. ¿Cuál es la finalidad de un currículo pertinente más que evitar el pensar de otro modo para llegar a otros modos de vida? Como afirma Hoyos-Vásquez (2009): "la educación en general y la universidad especialmente deben ser impertinentes y cuanto más impertinentes tanto más críticas y tanto más abiertas a la utopía" (p 427). 


\section{A manera de conclusión}

Hemos presentado brevemente los aspectos fundamentales del pensamiento pedagógico de Guillermo Hoyos Vásquez en torno a lo que sería su forma de encarnar el pensamiento crítico. Ahora bien, si se trata de ofrecer una caracterización (siempre posible de ampliar) del pensamiento crítico inspirada en el pensador colombiano, podría ser esta: el pensamiento crítico es una manera de ser que orienta el pensamiento desde el mundo de la vida (fenomenología) hacia el entendimiento compartido de la responsabilidad social (teoría crítica) por medio del diálogo, basado en la imaginación y el pensamiento de la razón que orientan la práctica cotidiana hacia utopías milenarias de la libertad y la felicidad (idealismo alemán).

Para Hoyos comenzamos a ser críticos al darnos por aludidos, al conmovernos, al sentirnos afectados por lo que pasa a nuestro alrededor. Se trata, por tanto, de sentir antes que entender, pero es precisamente este sentir el que parece bloqueado en la escuela, la universidad y las ciencias, acaso por el afán de objetividad e imparcialidad. Ciertamente, los profesores solemos pedir a nuestros estudiantes las razones que encuentran en el texto y razones que sustenten una crítica personal hacia la tesis o apartes del texto; poco, creo yo, pedimos que nos cuenten lo que sienten al ver lo que ocurre a su alrededor, que nos dejen ver su interior y exhiban sus sentimientos y emociones ante la injusticia y el sufrimiento del otro. iNi pensarlo, pensar críticamente es evaluar por razones válidas y objetivas! Nuestro pensar crítico se dirige a textos muertos, o mejor, mata los textos vivos que encontramos en los libros y los textos propios de nuestra situación al no considerarlos ni siquiera para su narración y lectura en clase.

En efecto, en la escuela aprendimos a desarrollar pertinentes análisis micro y macroestructurales a aquellos textos de las ciencias y humanidades, es decir nos centramos en el desarrollo cognitivo, mientras que el lado ético-político y el de la propia identidad ha quedado como un accesorio de mercado bajo el lema de una "educación integral". Ahora bien, lo que se propone desde esta reflexión no es de ninguna manera omitir tales ejercicios cognitivos, sino complementarlos con ejercicios que lleven a la escuela tanto los sentimientos y emociones, como las razones de cada cual, pero no como simple accesorio, sino como aspectos necesarios y transversales de la educación misma, del pensamiento crítico. Preguntar cuál es la tesis del texto, claro; pero también preguntar qué sintió al leerlo; preguntar qué piensa al respecto y cómo se podría cambiar.

Aplicado al ejercicio de la lectura en la escuela, imaginamos una lectura crítica que comience por cualquier texto que haga parte de la realidad del estudiante, de sus vivencias, desde las más complejas hasta las más triviales. Se trata de involucrar explícitamente la situación social, la justicia e injusticia, la dignidad e indignación, el reconocimiento y la humillación que abundan en las noticias. Ante estos textos, los sentimientos y emociones pueden aflorar y participar no solo de la evaluación racional de razones e ideas, sino de las acciones mismas que concurren con tales situaciones o que buscan su cambio. Así, leer críticamente incluiría el análisis estructural del texto, pero llegando "más allá o más acá" del entendimiento hasta un pensar que se nutre de los sentimientos y emociones, que alcanza a la utopía y el compromiso de realizarla. Por ejemplo, de preguntar al estudiante y de pensar, en medio de un diálogo enriquecido por diferentes perspectivas, sobre el mundo que proyecta el texto, qué siente sobre eso, qué utopías parece reflejar y proponer, de qué manera podría orientar su propia vida ante ese texto.

\section{Referencias}

Heidegger, M. (1981). Carta sobre el humanismo. Ediciones del 80.

Hoyos-Vásquez, G. (1998). Razón pura versus razón práctica: un debate contemporáneo en la enseñanza de la Filosofía. En Cuadernos de la oEI. Educación: currículos y didáctica. I La enseñanza de la Filosofía en el nivel medio. (pp. 75-112). OEI.

Hoyos-Vásquez, G. (2003). El ethos de la universidad. Monografías virtuales Ciudadanía, democracia y valores en sociedades plurales, (3). https://www.javeriana. edu.co/blogs/guillermo_hoyos/archives/113 
Hoyos-Vásquez, G. (2009). Educación para un nuevo humanismo. Magis, Revista Internacional de Investigación en Educación, 1 (2), 425-433.

Hoyos-Vásquez, G. (2011). Los intereses de la vida cotidiana $y$ las ciencias. Universidad Nacional de Colombia.

Hoyos-Vásquez, G. (2012a). Investigaciones fenomenológicas. Siglo del Hombre Editores.

Hoyos-Vásquez, G. (2012b). Ensayos para una teoría discursiva de la educación. Magisterio.

Hoyos-Vásquez, G. (2013). La comunicación como cambio de paradigma. En Filosofía de la Educación. Apuntes de su último seminario de doctorado. (pp. 35-61). Siglo del Hombre Editores y Universidad Pedagógica y Tecnológica de Pereira. https://www. oei.es/historico/valores $2 /$ monografias/monografia03/reflexion01.htm

Kant, I. (2003). Pedagogía. Akal.

Prada, M., Acevedo, D., y Prieto, F. (2019). Filosofía como forma de vida. Laboratorio de Escritura: Estrategia pedagógica. Aula de Humanidades.
Prieto, F. (2018). El pensamiento crítico y el autoconocimiento. Revista de Filosofía, 74, 173-191. http:// dx.doi.org/10.4067/S0718-43602018000100173

Ricoeur, p. (2010). Del texto a la acción. Ensayos de hermenéutica II. Fondo de Cultura Económica.

Ruiz, A. y Quintero, M. (2012) Prólogo. En Ensayos para una teoría discursiva de la educación. Magisterio.

Serna, J. (2013). Guillermo Hoyos Vásquez, un hombre de palabra. Revista Historia de la Educación Colombiana, 16(16), 21-24. https://revistas.udenar. edu.co/index.php/rhec/article/view/1737

Vargas, G. (2014). Guillermo Hoyos Vásquez: entre filosofía y pedagogía. En Los filósofos y la educación. Formación, didáctica y filosofía de la educación (pp. 11-33). Universidad Pedagógica Nacional.

Zuleta, E. (2005). Elogio a la dificultad y otros ensayos. Hombre Nuevo, Fundación Estanislao Zuleta. 